\title{
Ship motion-based wave estimation using a spectral residual-calculation
}

\author{
Nielsen, Ulrik D.; H. Brodtkorb, Astrid
}

Published in:

OCEANS'18 MTS/IEEE Kobe/Techno-Ocean 2018 (OTO'18)

Link to article, DOI:

10.1109/OCEANSKOBE.2018.8559136

Publication date:

2018

Document Version

Peer reviewed version

Link back to DTU Orbit

Citation (APA):

Nielsen, U. D., \& H. Brodtkorb, A. (2018). Ship motion-based wave estimation using a spectral residualcalculation. In OCEANS'18 MTS/IEEE Kobe/Techno-Ocean 2018 (OTO'18) IEEE.

https://doi.org/10.1109/OCEANSKOBE.2018.8559136

\section{General rights}

Copyright and moral rights for the publications made accessible in the public portal are retained by the authors and/or other copyright owners and it is a condition of accessing publications that users recognise and abide by the legal requirements associated with these rights.

- Users may download and print one copy of any publication from the public portal for the purpose of private study or research.

- You may not further distribute the material or use it for any profit-making activity or commercial gain

- You may freely distribute the URL identifying the publication in the public portal

If you believe that this document breaches copyright please contact us providing details, and we will remove access to the work immediately and investigate your claim 


\section{Ship motion-based wave estimation using a spectral residual-calculation}

\author{
Ulrik D. Nielsen ${ }^{(1,2)}$ \\ (1) DTU Mechanical Engineering \\ Technical University of Denmark \\ Kgs. Lyngby, Denmark \\ udn@mek.dtu.dk
}

\author{
Astrid H. Brodtkorb ${ }^{(2)}$ \\ ${ }^{(2)}$ NTNU AMOS \\ Norwegian University of Science and Technology \\ Trondheim, Norway \\ astrid.h.brodtkorb@ntnu.no
}

\begin{abstract}
This paper presents a study focused on a newly developed procedure for wave spectrum estimation using waveinduced motion recordings from a ship. The particular procedure stands out from other existing, similar ship motion-based procedures by its computational efficiency and - at the same time - providing accurate estimates of the on-site wave conditions. In the paper, the procedure is applied to full-scale experimental data obtained from dedicated sea trial runs. The results show favorable agreement with corresponding wave spectrum estimates by a directional wave buoy.
\end{abstract}

Index Terms-Wave spectrum estimation, ship motions, spectral residual calculation, full-scale experimental data

\section{INTRODUCTION}

High levels of safety and fuel efficiency are fundamental and strived for in all types of ship operations at sea. Notably, it will be essential to have reliable performance evaluations of safety and fuel efficiency levels - in real-time and at the exact point of operation - when the autonomous ship starts to navigate the world's oceans in a (not so...) distant future; pointing out that human gut-feeling to secure safety and efficiency has been taken out of the loop. The governing factor influencing, or compromising, the achievement of safe and efficient operations is the wave-induced loads on the particular vessel. As a consequence, it is fundamentally important to possess realtime knowledge about the existing wave conditions at the very location of the ship or marine vessel. Having this sort of information available allows not only an evaluation of the past and current safety and fuel performance levels but the information can also be applied as input to decision support systems which aid to increasing the future levels. It is thus a crucial and relevant engineering task to be able to estimate the on-site sea state, usually represented by the wave energy spectrum, since it is the fundamental input regardless if the concern is on evaluation of past conditions or on predictions of the future performance level of marine operations.

Trustful means for sea state estimation include floating (classical) wave buoys, which are primary tools used to collect statistical ocean wave data. However, wave buoys are not practical for a sailing vessel, since sea state information, in realtime and at the actual geographical position, is required. On

\footnotetext{
This work was supported by the Research Council of Norway through the
} Centres of Excellence funding scheme, project number 223254 AMOS. the other hand, the analogy between a ship and a floating buoy naturally suggests to using the ship itself as a kind of wave buoy [1]-[7]. In this analogy, the overall principle, or problem, is a matter of fusing together signals of measured waveinduced responses of the particular vessel with a mathematical model relating the signals of interest and the actual wave conditions, i.e. the wave energy spectrum. It is noteworthy that this study uses motion components (heave, roll, pitch) as input to the estimation algorithm, but it is possible also to use, e.g., the wave-induced (vertical) bending moment amidships [8] if measurements and the corresponding transfer function are available.

In the past, several successful studies on the wave buoy analogy have been conducted, and it has been concluded [9] that different procedures can be applied. Nonetheless, the underlying computational/mathematical methods have been found to suffer in many cases of being too slow or inefficient (although being fairly accurate). Recently, however, a novel procedure has been developed by Brodtkorb et al. [10] and Nielsen et al. [11], where the former study considers stationkept, dynamically positioned ships exclusively, while the latter [11] focuses on ships with a non-zero forward speed, and to some extent represents a generalisation of the former. Regardless of forward speed, the procedure relies on a bruteforce, residual calculation formulated in the frequency domain through spectral analysis and, indeed, this solution-strategy is what makes the particular procedure computationally very efficient with computational times in the order of a few seconds.

This paper is a direct continuation of the previous work [11] addressing sea state estimation from ships advancing in the seaway. The original work [11] was focused on comprehensively testings and evaluations of the estimation algorithm using numerical simulations of motion measurements, while testings with full-scale experimental data were made on only a few cases. In the present paper, the method is tested on additional sets of full-scale motion recordings obtained during sea trials with a research vessel. The performance of the estimation algorithm is evaluated by comparing the produced wave spectrum estimates with corresponding spectrum measurements from a wave buoy deployed for the special purpose. The paper has its main focus on the results, Sections III 
and IV, obtained from the experimental data, and in the following section the estimation procedure is briefly presented; introducing only the fundamentals as the details are given in [11].

\section{Methodology And estimation PROCEDURE}

It is a general characteristic of the wave buoy analogy that it relates the measured signals of wave-induced responses with the exciting unknown wave spectrum through a mathematical model that couples the two parts using theoretically calculated transfer functions. Thus, in a short-crested, stationary seaway, the governing equation reads,

$$
R_{i j}\left(\omega_{e}\right)=\int X_{i}\left(\omega_{e}, \mu+\chi\right) \overline{X_{j}\left(\omega_{e}, \mu+\chi\right)} S_{e}\left(\omega_{e}, \mu\right) d \mu
$$

where $R_{i j}\left(\omega_{e}\right)$ is the complex-valued cross spectrum for a pair $(i, j)$ taken among, say, the heave $(z)$, roll $(\phi)$, and pitch $(\theta)$ responses $i, j=\{z, \phi, \theta\} ; \overline{X_{j}(\ldots)}$ is the complex conjugate of the (complex-valued) transfer functions in heave, roll and pitch. $S_{e}\left(\omega_{e}, \mu\right)$ is the directional wave spectrum ordinate due to waves from direction $\mu$, relative to the mean wave heading $\chi$, as observed from the advancing ship, and $\omega_{e}$ is the encounter frequency. As noted $\mu$ represents the direction of the single waves, and, hence, by integration over all directions, the mean (absolute) wave direction $\vartheta$ can be derived by taking into account the compass-course of the vessel. The encountered frequency is related to the absolute frequency $\omega_{0}$ through the Doppler Shift,

$$
\omega_{e}=\omega_{0}-\omega_{0}^{2} \psi, \psi=\frac{U}{g} \cos \chi
$$

where $g$ is the acceleration of gravity and $U$ is vessel speed, and setting $\mu=0$ for simplicity. The Doppler Shift imposes an elementary physical problem but, in practice, this shift implies that the wave estimation problem is rather "delicate" to solve for ships with advance speed; noting that, in the end, the absolute wave energy spectrum rather than the encountered wave energy spectrum must be estimated. Several textbooks introduce the complications involved because of the Doppler Shift, e.g. [12]-[14], but giving no solution on how to deal with the problem in practice, when a wave spectrum (or a response spectrum) shall be transformed from encounter frequencydomain to absolute frequency-domain; a process that theoretically cannot be uniquely solved as it relates one single encounter frequency to three absolute frequencies in following seas. On the other hand, an interrelated study by Nielsen [15] outlines explicitly an elaborate and practical solution strategy for this problem. The details of the particular work will not be covered herein, but later additional referencing will be made to the study [15].

The main (mathematical) task of the wave estimation problem is to solve Eq. (1) for the unknown wave spectrum. The actual solution follows from an iterative approach, schematically written as;

$$
\begin{aligned}
\tilde{R}_{i j}\left(\omega_{e}\right) & =R_{i j}\left(\omega_{e}\right)-\hat{R}_{i j}\left(\omega_{e}\right) \\
\hat{E}_{i j}\left(\omega_{e}\right) & =\hat{E}_{i j}\left(\omega_{e}\right)+h \tilde{R}_{i j}\left(\omega_{e}\right) \\
\hat{R}_{i j}\left(\omega_{e}\right) & =\hat{E}_{i j}\left(\omega_{e}\right) \int X_{i}\left(\omega_{e}, \mu+\chi\right) \overline{X_{j}\left(\omega_{e}, \mu+\chi\right)} d \mu
\end{aligned}
$$

performed for any pair $(i, j)$ of response signals for the entire set of considered encounter frequencies. The directional wave spectrum is taken as the product between a point wave spectrum $E_{i j}\left(\omega_{e}\right)$ and a spreading function $\varphi(\mu)$, e.g. [12]. The iteration is initiated by setting the estimated response spectrum and the estimate of the wave spectrum equal to zero; emphasising that $\hat{E}_{i j}\left(\omega_{e}\right)$ is computed for each combination of signals. As seen, the iteration builds on a residual calculation (Eq. 3a), where $\hat{R}_{i j}\left(\omega_{e}\right)$ is an estimate of the measured (response) cross spectrum $R_{i j}\left(\omega_{e}\right)$. Subsequently, the residual $\tilde{R}_{i j}\left(\omega_{e}\right)$ facilitates an update (Eq. 3b) of the wave spectrum estimate, using a prescribed step size $h>0$, and the wave spectrum is in turn used to estimate the cross spectrum again (Eq. 3c). This iteration is continued until a threshold is reached $\left|\tilde{R}_{i j}\right| \leq \epsilon$, for $\epsilon>0$.

The iteration scheme (Eqs. 3a-3c) is as mentioned applied for each signal-combination $(i, j)$ but, although not mentioned in this paper, it is a fact that the iteration is, on top, conducted for a discrete set of absolute wave directions specified on the full circle, $\vartheta=0-360 \mathrm{deg}$.. Altogether, the solutions obtained from Eqs. (3a-3c) are a set of initial brute-force estimates of the encounter-wave energy spectrum. Therefore, in order to obtain the one final spectrum estimate, valid in the absolute domain, some further postprocessing steps are required. The details of this postprocess are given in [11], and here the basics should be given only. Basically, the postprocess consists of two steps: Firstly, a corresponding match of the optimum wave direction and an associated set of wave spectra (composed by all signal-combinations) is selected through a minimisation of a metric based on an energy-variance between the individual wave spectra. Secondly, for the particular wave direction, the mean wave spectrum of the set of wave spectra is calculated and, lastly, this spectrum is transformed [15] to the absolute (frequency) domain.

In the original work [11] the developed estimation procedure has been tested intensively (and successfully) using numerically simulated data, and the method was also applied to a few full-scale data sets obtained from sea trials. In the remaining part of the present paper, additional sets of sea trials data will be used to evaluate the performance of the estimation procedure.

\section{MOTION RECORDINGS FROM SEA TRIALS}

Full-scale motion measurements have been recorded during a test campaign with a smaller research vessel, $R / V$ Gunnerus owned and operated by the Norwegian University of Science and Technology. Details of the test campaign and its various elements are described by [16] but basically the sea trials 
TABLE I: Operational data during runs and standard deviations of motion measurements.

\begin{tabular}{cccccccc}
\hline & $\begin{array}{c}\text { Power } \\
{[\mathrm{kW}]}\end{array}$ & $\begin{array}{c}\text { Course } \\
{[\text { deg. }]}\end{array}$ & $\begin{array}{c}\text { SOG } \\
{[\mathrm{kts}]}\end{array}$ & $\begin{array}{c}\text { STW } \\
{[\mathrm{kts}]}\end{array}$ & $\begin{array}{c}\text { Heave } \\
{[\mathrm{m}]}\end{array}$ & $\begin{array}{c}\text { Roll } \\
{[\mathrm{deg} .]}\end{array}$ & $\begin{array}{c}\text { Pitch } \\
{[\text { deg. }]}\end{array}$ \\
\hline ID03 & $2 \times 250$ & 115 & 10.3 & 10.0 & 0.5 & 2.6 & 1.2 \\
ID04 & $2 \times 250$ & 080 & 10.3 & 10.3 & 0.5 & 3.1 & 0.8 \\
ID05 & $2 \times 375$ & 260 & 11.4 & 11.3 & 0.6 & 3.0 & 1.0 \\
ID06 & $2 \times 375$ & 340 & 11.1 & 11.1 & 0.7 & 1.9 & 2.0 \\
ID07 & $2 \times 375$ & 205 & 10.7 & 10.7 & 0.5 & 2.9 & 1.2 \\
ID08 & $2 \times 375$ & 025 & 11.0 & 11.7 & 0.6 & 3.1 & 1.6 \\
ID09 & $2 \times 375$ & 165 & 10.8 & 10.8 & 0.4 & 2.3 & 1.2 \\
ID10 & $2 \times 375$ & 315 & 11.5 & 11.5 & 0.6 & 2.4 & 1.8 \\
\hline
\end{tabular}

included dynamic positioning tests as well as seakeeping tests. The present study focuses on a set of seakeeping tests from which motions measurements were available. The sea trials were conducted in a restricted ocean area in the Norwegian Sea outside the fiords of Trondheim, and the seakeeping tests had run paths as illustrated in Figure 1. Generally, the individual 'straight-line runs' lasted 20-25 minutes and the runs were all conducted at constant engine power and at constant (compass) course, striving to maintain the relative wave heading fixed. Operational parameters including energy levels, in terms of standard deviations, of the wave induced motions (heave, roll, pitch) are given in Table I. As part of the test campaign, a
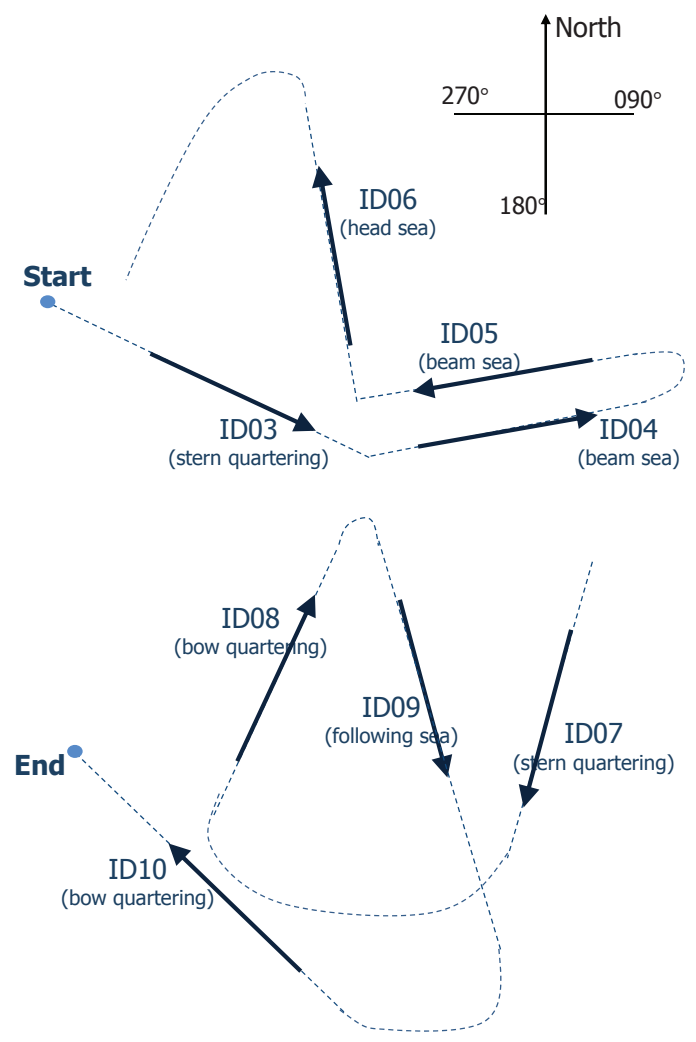

Fig. 1: Vessel run paths during sea trials; IDs 03-06 at top and IDs 07-10 at bottom with a very short transition time in between all runs. The (visually) observed wave heading is included in parentheses; noting that the observed wave direction was nearly the same during all runs, with waves coming from North North-East. free-floating wave buoy [17] was deployed to provide the wave conditions during the sea trials.

In Section II, it was made clear that the complex-valued transfer functions are needed for the considered set of measured motion signals. In this study, use is made of the heave, roll and pitch motions and, hence, corresponding (wave-ship) transfer functions have been calculated with a 2D strip theory code [18].

\section{RESULTS AND DISCUSSIONS}

The (final) output of the estimation procedure is a $2 \mathrm{D}$ wave energy spectrum and an associated wave direction, equivalently relative wave heading; where $\chi=180 \mathrm{deg}$. is head sea, $090 \mathrm{deg}$. and $270 \mathrm{deg}$. are beam sea approaching on port side and starboard side, respectively. The results corresponding to the individual runs, cf. Figure 1, are presented in the plots in Figures 2 and 3. It is seen that each plot contains the wave spectrum estimate of the spectral residual calculation and the corresponding result from the buoy measurements. The single wave spectrum estimates lead immediately to a set of integrated wave parameters, and the results are summarised in Table II for significant wave height $H_{s}$, mean wave period $T_{1}$, spectral peak period $T_{p}$, and mean (absolute and approaching) wave direction $\vartheta$, with the relative wave heading included in parenthesis for the ship motion-based results. The formulas of integrated wave parameters can be found in any textbook related to ocean engineering and ship dynamics, e.g. [12], [19].

Generally, the plots in Figures 2 and 3 reveal a reasonable agreement between the spectrum estimates from the two 'sources', i.e the ship motions and buoy measurements, respectively. In this context, it should be kept in mind that, strictly speaking, there exists no exact, true spectrum; the spectrum estimate will be but just an estimate, even if the spectrum originates from a wave buoy. Indeed, this fact should be remembered when comparing the corresponding sets of spectrum estimates obtained during the studied sea trial runs; if not by other reasons, then simply because the buoy and the ship are never at exactly the same position at any time, as the buoy is floating at a (nearly) fixed position, whereas the ship is advancing in the sea. Nonetheless, the buoy measurements are

TABLE II: Wave parameter estimates based on ship motions using the spectral residual approach ('Ship'), and the corresponding estimates by a free-floating wave buoy ('Buoy'). Significant wave height $H_{s}$; mean period $T_{1}$; peak period $T_{p}$; mean direction $\vartheta$, with the estimated wave heading in parenthesis for the ship motion-based results.

\begin{tabular}{|c|c|c|c|c|c|c|c|c|}
\hline & \multicolumn{2}{|c|}{$H_{s}[\mathrm{~m}]$} & \multicolumn{2}{|c|}{$T_{1}[\mathrm{~s}]$} & \multicolumn{2}{|c|}{$T_{p}[\mathrm{~s}]$} & \multicolumn{2}{|c|}{$\vartheta_{\text {mean }}[$ deg.] } \\
\hline & Ship & Buoy & Ship & Buoy & Ship & Buoy & Ship & Buoy \\
\hline ID03 & 2.3 & 2.2 & 7.9 & 7.0 & 9.3 & 9.7 & $345(050)$ & ) 342 \\
\hline ID04 & 1.9 & 2.4 & 7.6 & 7.4 & 10.0 & 9.9 & $335(075)$ & 343 \\
\hline ID05 & 2.1 & 2.6 & 9.1 & 7.2 & 10.5 & 9.5 & $335(255)$ & 346 \\
\hline ID06 & 3.0 & 3.1 & 8.0 & 4.4 & 9.7 & 9.3 & $350(190)$ & 346 \\
\hline ID07 & 2.3 & 2.3 & 8.9 & 7.1 & 10.1 & 9.6 & $330(305)$ & 338 \\
\hline ID08 & 2.3 & 2.2 & 9.0 & 7.2 & 9.6 & 9.5 & $340(135)$ & 342 \\
\hline ID09 & 2.2 & 2.1 & 8.0 & 7.0 & 11.8 & 9.4 & $335(350)$ & 323 \\
\hline ID10 & 2.3 & 2.2 & 9.0 & 6.8 & 9.1 & 9.3 & $355(220)$ & 349 \\
\hline
\end{tabular}


used as the base metric and, hence, relative deviations between the two sets of results can be calculated by studying the integrated wave parameters derived from the sets of spectra. Thus, relative deviations $\epsilon$ are computed as

$$
\begin{aligned}
\epsilon_{\alpha} & =\frac{\alpha_{\text {ship }}-\alpha_{\text {buoy }}}{\alpha_{\text {buoy }}} \cdot 100 \% \\
\epsilon_{\vartheta} & =\frac{\vartheta_{\text {ship }}-\vartheta_{\text {buoy }}}{360 \mathrm{deg} .} \cdot 100 \%
\end{aligned}
$$

where $\alpha$ should be substituted with the particular wave parameter in question. The comparisons of significant wave height $\left(H_{s}\right)$, wave periods $\left(T_{1}, T_{p}\right)$, and wave direction $(\vartheta)$ have been plotted in Figure 4. The main observation from the plots is that the energy level, represented by $H_{s}$, and the wave direction can be estimated with the highest accuracy, whereas
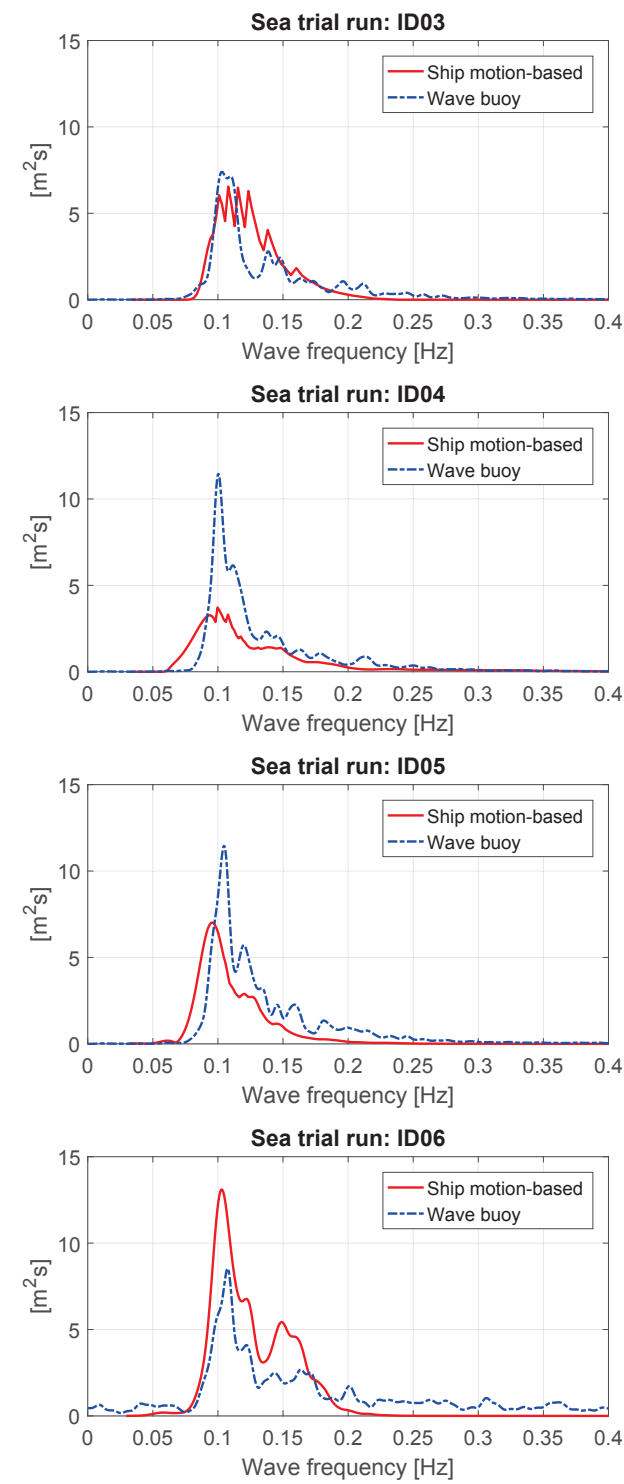

Fig. 2: Wave spectrum estimates, at absolute frequency scale, in runs ID03 to ID06 with results based on ship motions, red full line, and buoy measurements, dashed blue line. the wave periods $T_{1}$ and $T_{p}$, being representative numbers of the frequency-wise distribution of energy, tend to take (too) high values. This particular observation is no surprise but rather it is a consequence of the filtering characteristic of a vessel in waves, making the ship less responsive to highfrequency waves, relatively to ship length (and breadth); as has been reported in a wide number of other publications about the wave buoy analogy.

When a more detailed inspection of the spectrum estimates, Figs. 2 and 3, is made a few remarks and observations are noteworthy: (1) The spiky behaviour of the ship motion-based result in cases ID03 and ID07 is not fully understood but the 'spikyness' occurs (seemingly) only in the stern-quartering cases. Obviously, the spiky behaviour could easily be reduced or removed by introducing smoothing to the presented
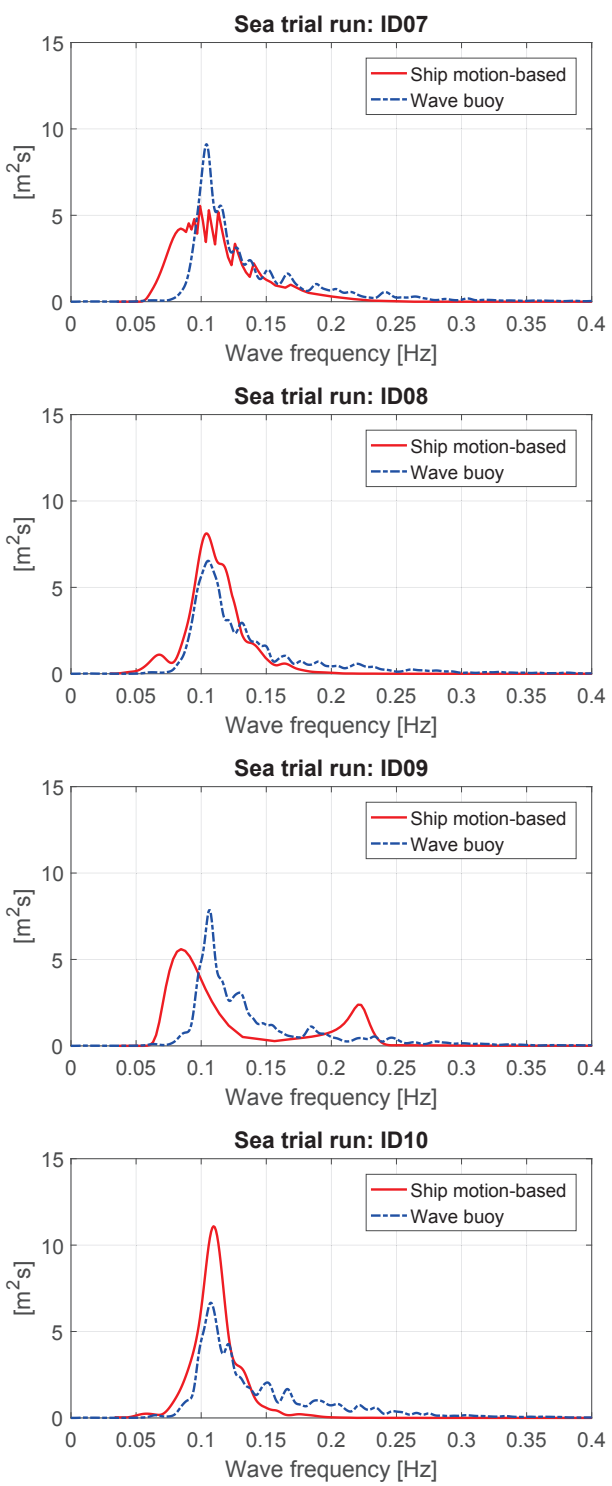

Fig. 3: Wave spectrum estimates, at absolute frequency scale, in runs ID07 to ID10 with results based on ship motions, red full line, and buoy measurements, dashed blue line. 

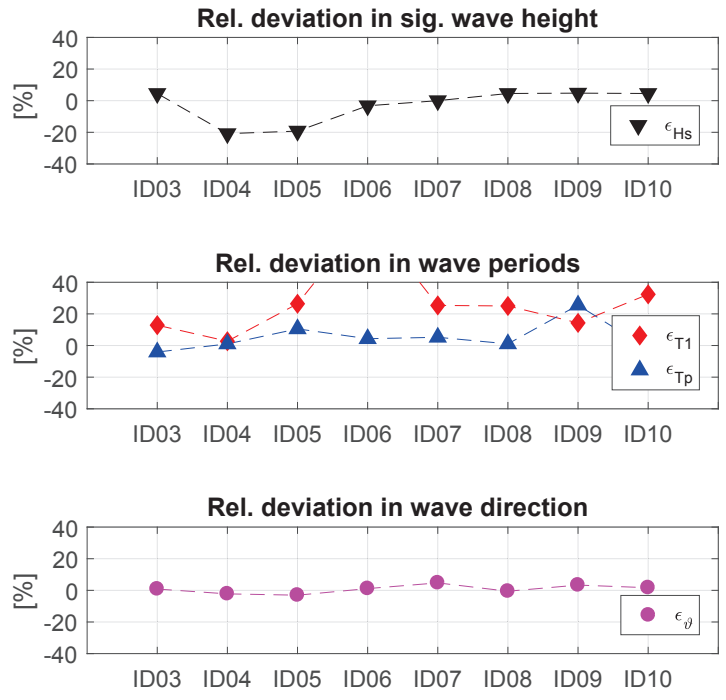

Fig. 4: Relative deviation between integrated wave parameters, including wave direction, derived from spectrum estimates using ship motions and buoy measurements, respectively.

spectrum estimates. (2) Although smoothing of the (final) wave spectrum estimate is not a part of the postprocessing, smoothing is indirectly applied, since smoothing is introduced in the initial cross spectral analysis of the responses. However, varying the degree of smoothing on the cross spectra has little effect on the overall outcome of the spectrum estimates (not shown herein), and increased smoothing does not exclude the spiky behaviour of cases ID03 and ID07. (3) The estimate by the free-floating wave buoy in case ID06 seems to be "corrupted" with white noise, noting that no postprocessing of the buoy measurements has been made. The specific case (ID06) has the highest energy level (significant wave height) and, interestingly, with the results of buoy and ship being comparable. The larger wave energy level of this case is reflected by the response energy levels, cf. Table I, of the particular case. (4) The wave spectrum estimate in case ID09, using ship motions, is inconsistent to all other cases using ship motions, and also to the buoy estimate of the same case. The shift of 'peak energy' to lower absolute frequency and the appearance of a substantial amount of wave energy at higher frequencies $(0.20-0.25 \mathrm{~Hz})$ are therefore considered erroneous results.

Some of the above observations can be investigated closer by considering the initial 'brute-force estimated wave spectrum', which applies to the encounter frequency-domain. Thus, the whole set of estimated encounter-wave spectra are shown in Figures 5 and 6. Obviously, the corresponding wave spectra - in absolute domain - seen previously in Figures 2 and 3 have been obtained by transformation of the encounter-wave spectra by applying the particular transformation algorithm [15], specifically developed to transform a spectrum from encounter to absolute domain, but not the "other way". The reason to transform to absolute domain is that the estimated encountered wave spectrum cannot be used to deduce any consequence of speed or heading changes of the vessel, which is the objective of decision support systems and also in more general response calculations. The problem of encounter domain is clearly visualised by the set of encounter-wave spectra (Figs. 5 and 6) which shows that the distribution of energy depends on the specific set of encounter frequencies that, in turn, depends on vessel advance speed and wave heading for the specific situation. This has an additional consequence, namely that comparison of the spectra cannot be (directly) made. Nonetheless, it is judged that no single one of the encounter-wave spectra appears to be of a special concern; including that of case ID09, noting that this spectrum is estimated in truly following waves $(\chi=350 \mathrm{deg}$.) for what reason the peak of the spectrum is at the very lowest estimated (encounter) frequency. Consequently, the "inconsistent" wave spectrum estimate of case ID09, in absolute frequency domain (cf. Fig. 3), is likely a result of an erroneous transformation imposed by the (postprocessing) transformation algorithm [15]. This judgement can be partly confirmed by inspection of the calculated, i.e. estimated, set of response spectra (heave, roll, pitch), obtained by using the estimated encounter-wave spectrum (derived for only the ship motion-based results). Thus, Figures 7 and 8 present comparisons between the measured and the calculated response spectra of all cases (ID03-ID10). As can be seen, the comparisons are of similar agreement for the various cases, with no real difference(s) to be observed from case ID09, strongly indicating that the problem with the estimated wave spectrum of this case has to do with the post-processed solution, where the transformation algorithm [15] is the responsible cause. Obviously, this calls for further studies of the transformation algorithm; and, although this is an exercise left for future work, an additional remark is also about the actual value of forward speed. If concern is on resistance and general hydrodynamic calculations it is always speed-through-water which is important, but for sea state estimation it is not entirely so. The results of the waveto-motion transfer functions are affected by forward speed, and here speed-through-water is the important one, but the main influence of forward speed, considering ship motion-based sea state estimation, is believed to be related to the mapping between encounter and absolute (wave) frequencies, governed by the Doppler Effect. In this sense, it will be the relative speed between waves and vessel which is the important parameter and, hence, vessel speed-over-ground should be used. On the other hand, should the speed of the waves themselves be measured relative to any sea current (not to mention depth dispersion)? Altogether it is not obvious what the actual value of forward speed should be and, hence, it could be relevant to look closer into this specific topic in another future study.

With a repeated view on the encounter-wave spectra (Figs. 5 and 6), it can be seen that the spikes of the spectra of cases ID03 and ID07 occur even before the transformation to absolute domain is made, as was also indicated previously, for what reason the transformation algorithm [15] is not the suspect in this case. Moreover, it can be seen from the figures that (nonphysical) spikes also appear at other cases, where the 

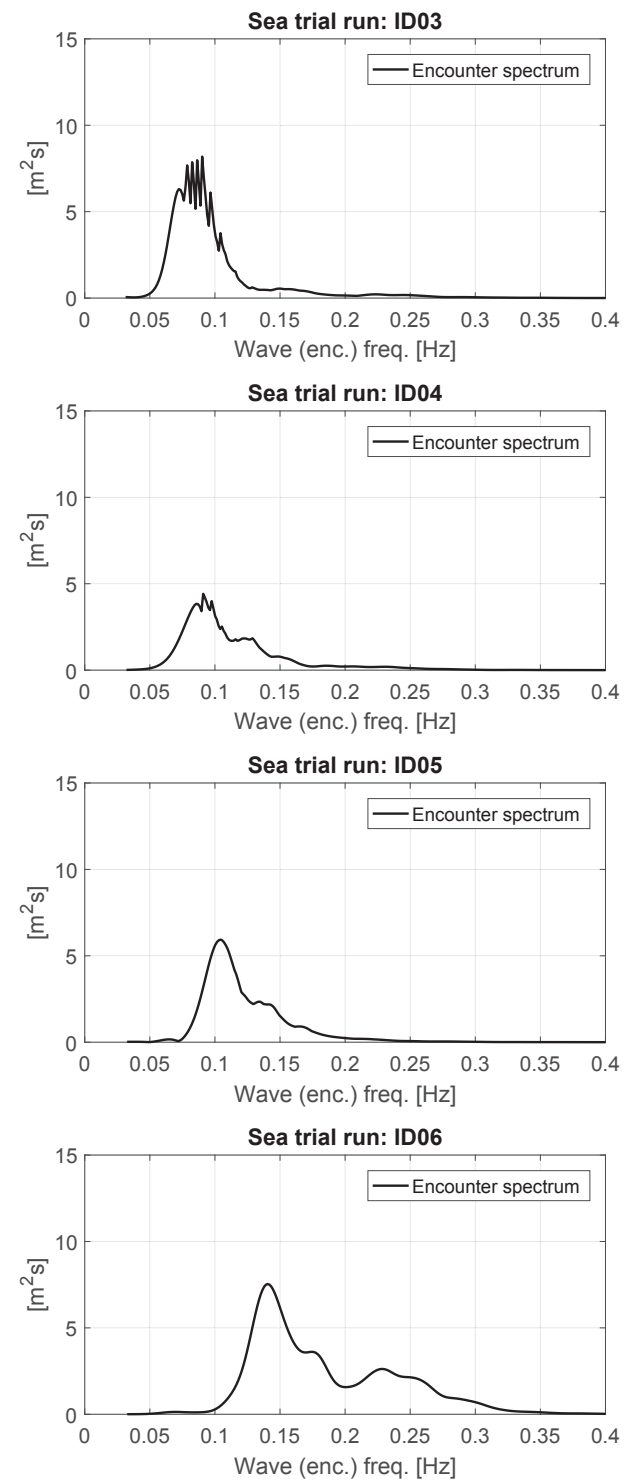

Fig. 5: Estimated encounter wave spectra of cases ID03-ID06.

ship experiences following sea, to smaller of larger degree (ID04 and ID09). However, by nature, the kind of spikes should not occur, and it should therefore be considered to introduce smoothing as part of the postprocessing of the wave spectrum estimates. An example is shown in Figures 9 and 10 for all spectra (cases ID03-ID10), where smoothing is imposed by simply using a moving average filter.

\section{SUMMARY AND CONCLUDING REMARKS}

In the paper it was shown that a newly developed procedure, using wave-induced motion recordings from an advancing ship, can successfully be used to provide wave spectrum estimates. The procedure relies on a spectral residual-calculation formulated through a brute-force iterative process, leading to an initial wave spectrum estimate in the encounter domain, and, as a result, the estimate must be subsequently transformed to absolute domain, applying a certain transformation algo-
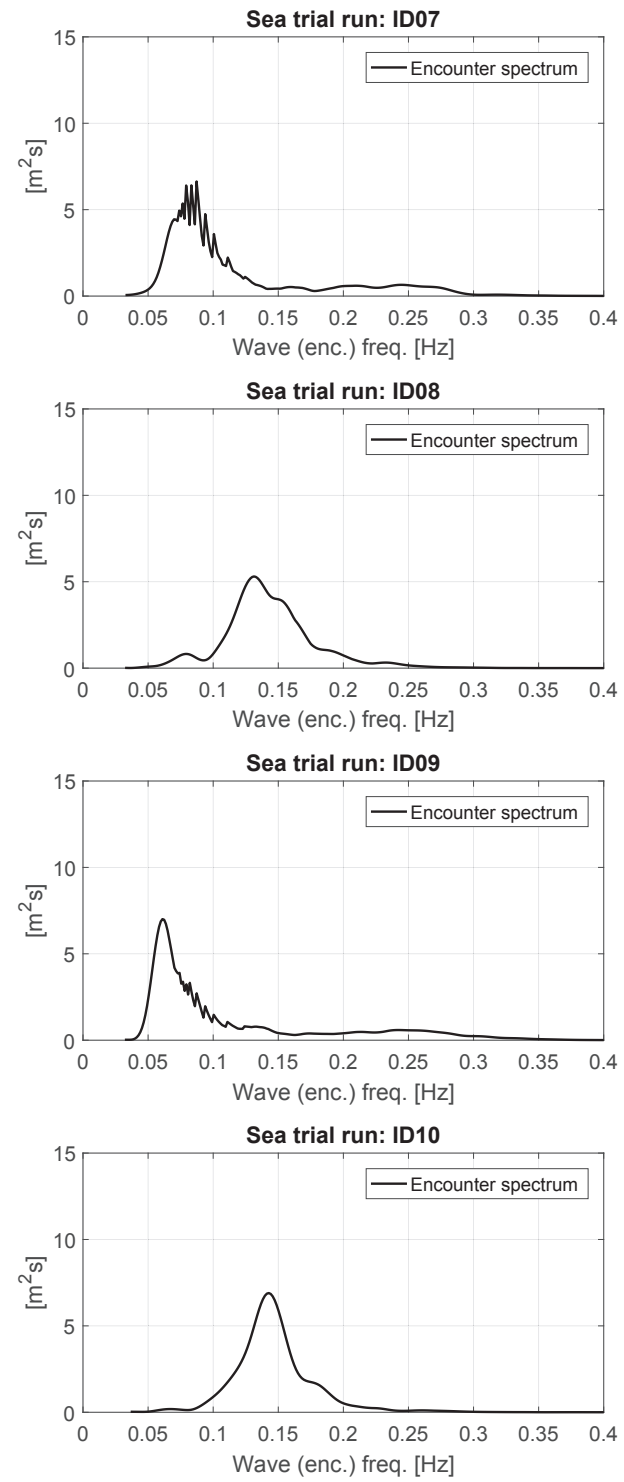

Fig. 6: Estimated encounter wave spectra of cases ID07-ID10.

rithm for the purpose. The iterative process and the associated transformation has proven very computationally efficient with CPU times in the order of a few seconds.

Specifically, the estimation procedure has been applied to full-scale experimental data obtained from sea trials, where wave spectrum estimates made by a free-floating wave buoy were also available. Generally, the respective sets of wave spectrum estimates were comparing well. One exception was however observed in a following sea condition, where the estimation procedure, using ship motions, was not able to accurately estimate the wave spectrum, with the cause being likely related to the specific transformation algorithm [15].

In the further work with the estimation procedure it is therefore suggested to focus on the influence of the transformation algorithm and, if possible, improve it. Furthermore, and as an interrelated study, the sensitivity to the actual value of forward speed should be addressed. 

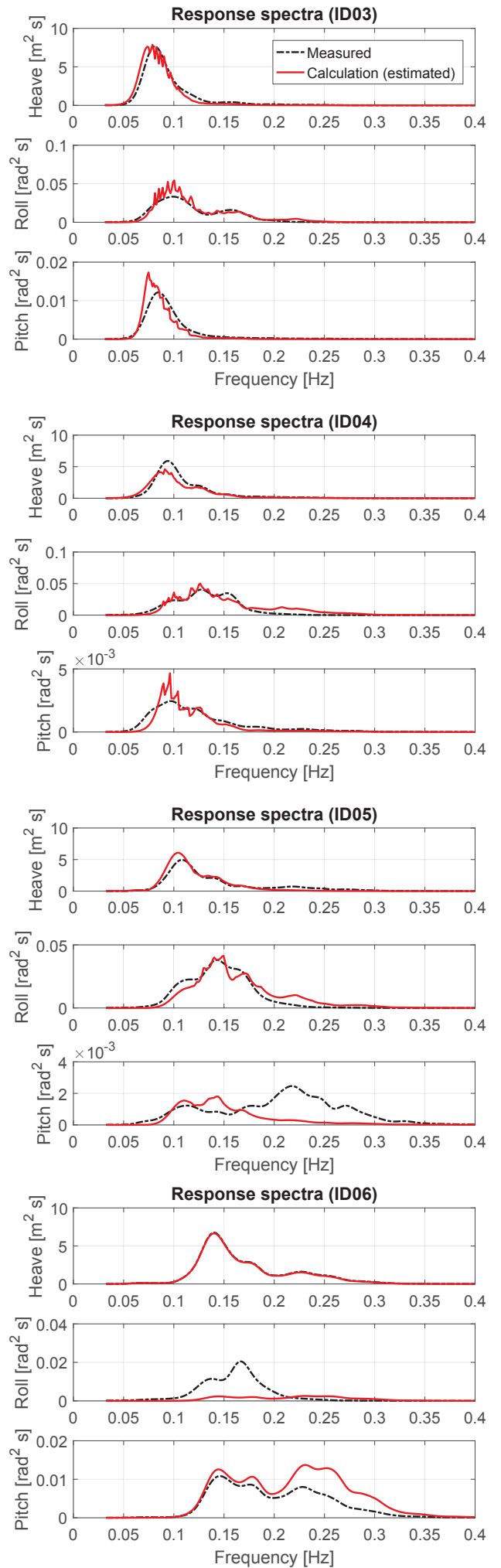

Fig. 7: Comparisons between measured response spectra and calculated spectra obtained using the estimated encounter-wave spectrum of the individual case, i.e. cases ID03-ID06. Note the difference on the y-scale.
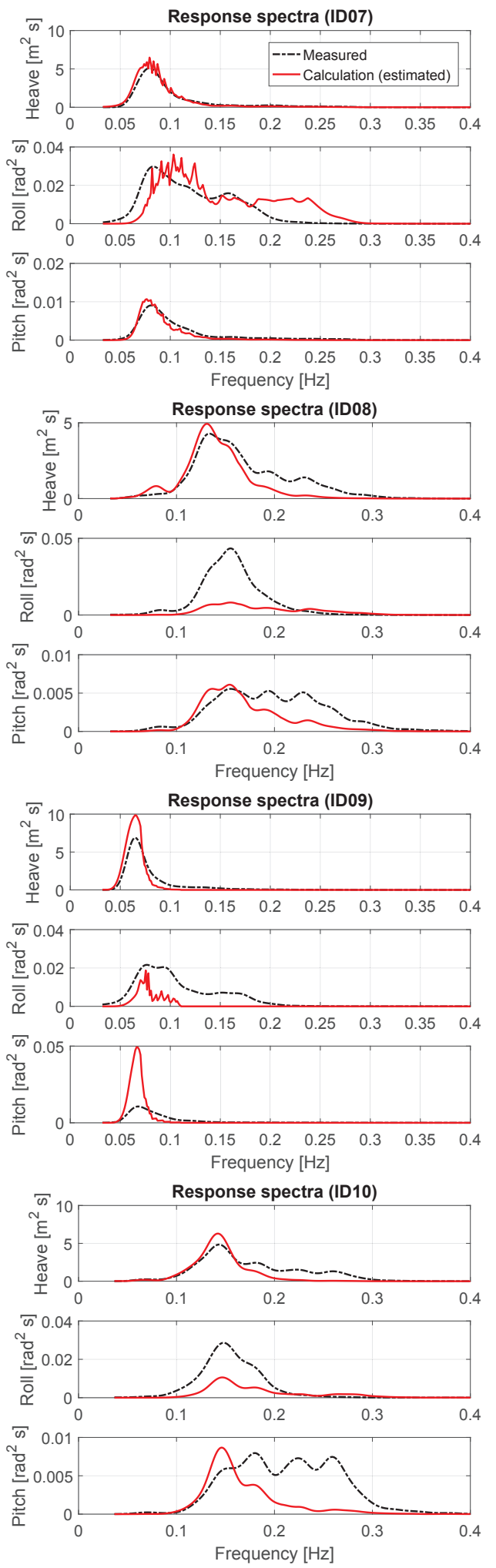

Fig. 8: Comparisons between measured response spectra and calculated spectra obtained using the estimated encounter-wave spectrum of the individual case, i.e. cases ID07-ID10. Note the difference on the $y$-scale. 

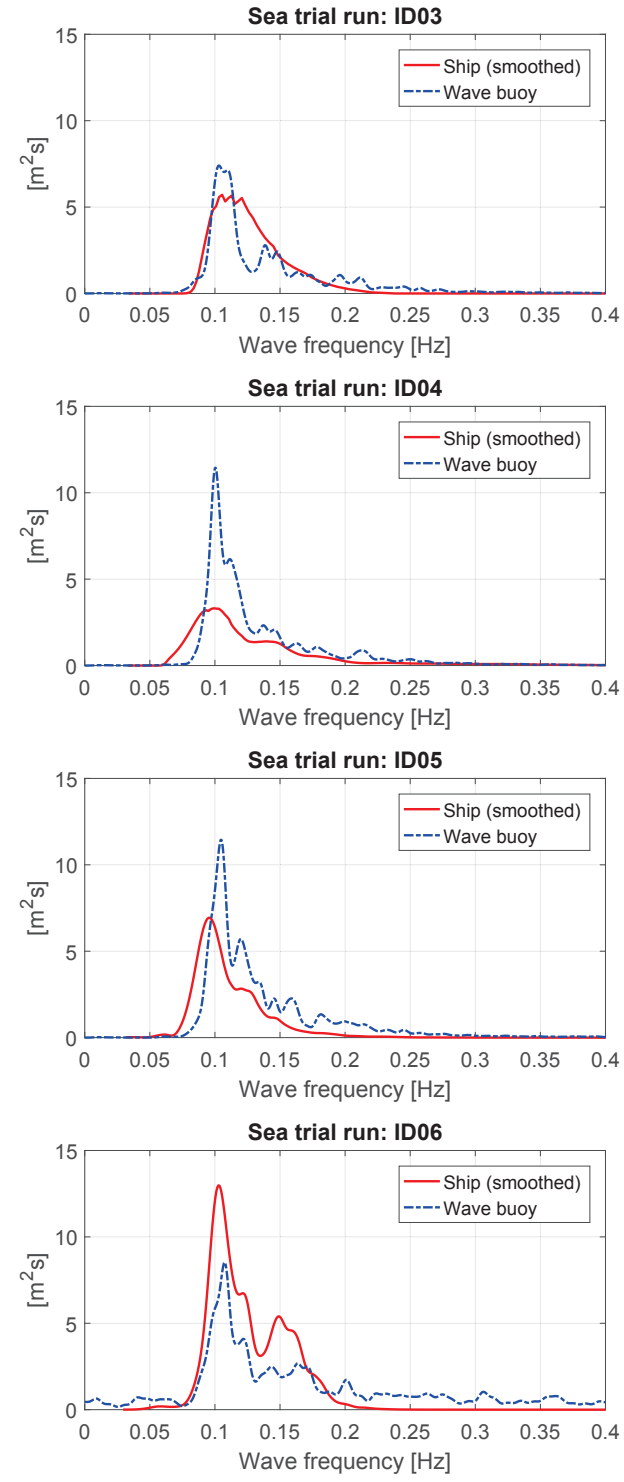
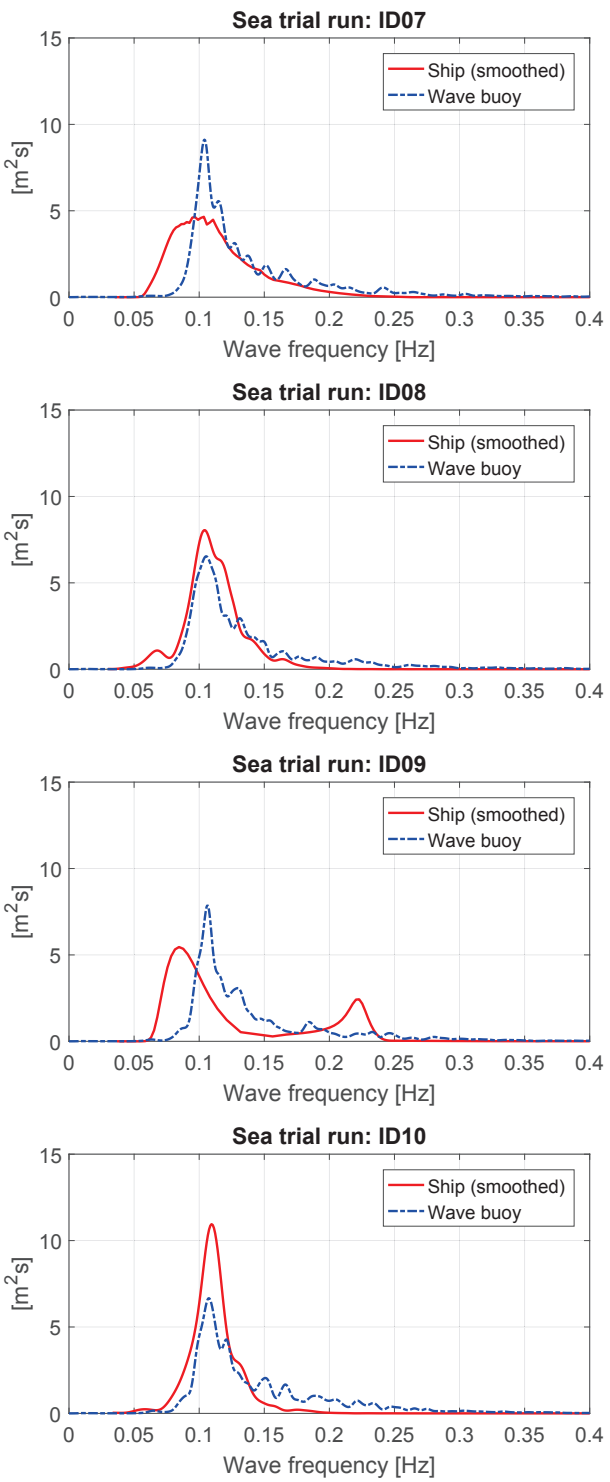

Fig. 10: Wave spectrum estimates being smoothed, compare to Fig.

Fig. 9: Wave spectrum estimates being smoothed, compare to Fig. 2. 


\section{ACKNOWLEDGMENT}

The presented data was collected by the SIMVAL KPN project financed through grant number $225141 / \mathrm{O} 70$ by RollsRoyce Marine and the Norwegian Research Council. Thanks to Rolls-Royce Marine for permission to publish the results.

\section{REFERENCES}

[1] T. Iseki and K. Ohtsu, "Bayesian estimation of directional wave spectra based on ship motions," Control Engineering Practice, vol. 8, pp. 215219, 2000.

[2] E. A. Tannuri, J. V. Sparano, A. N. Simos, and J. J. Da Cruz, "Estimating directional wave spectrum based on stationary ship motion measurements," Applied Ocean Research, vol. 25, pp. 243-261, 2003.

[3] R. Pascoal, C. Guedes Soares, and A. J. Sørensen, "Ocean Wave Spectral Estimation Using Vessel Wave Frequency Motions," Journal of Offshore Mechanics and Arctic Engineering, vol. 129, pp. 90-96, 2007.

[4] R. Pascoal, L. P. Perera, and C. Guedes Soares, "Estimation of Directional Sea Spectra from Ship Motions in Sea Trials," Ocean Engineering, vol. 132, pp. 126-137, 2017.

[5] U. D. Nielsen, "Estimations of on-site directional wave spectra from measured ship responses," Marine Structures, vol. 19, pp. 33-69, 2006.

[6] U. D. Nielsen, "Introducing two hyperparameters in Bayesian estimation of wave spectra," Probabilistic Engineering Mechanics, vol. 23, pp. 8494, 2008.

[7] N. Montazeri, U. D. Nielsen, and J. J. Jensen, "Estimation of wind sea and swell using shipboard measurements - A refined parametric modelling approach," Applied Ocean Research, vol. 54, pp. 73-86, 2016.

[8] U. D. Nielsen, J. J. Jensen, P. T. Pedersen, and Y. Ito, "Onboard monitoring of fatigue damage rates in the hull girder," Marine Structures, vol. 24, pp. 182-206, 2011.

[9] U. D. Nielsen, "A concise account of techniques available for shipboard sea state estimation," Ocean Engineering, vol. 129, pp. 352-362, 2017.

[10] A. H. Brodtkorb, U. D. Nielsen, and A. J. Sørensen, "Sea State Estimation Using Vessel Response in Dynamic Positioning," Applied Ocean Research, vol. 70, pp. 76-86, 2018.

[11] U. D. Nielsen, A. H. Brodtkorb, and A. J. Sørensen, "A bruteforce spectral approach for wave estimation using wave-induced vessel responses," Marine Structures (under review), 2018.

[12] R. Bhattacharyya, Dynamics of Marine Vehicles, John Wiley \& Sons, 1978.

[13] R.F. Beck, W.E. Cummins, J.F. Dalzell, P. Mandel, and W.C. Webster, "Vol. III: Motions in Waves and Controllability," in Principles of Naval Architecture, Second Revision, E.V. Lewis, Ed., pp. 1-188. SNAME, 1989.

[14] J.M.J. Journée and W.W. Massie, "Offshore Hydromechanics," January 2001, Lecture notes in course offered at TU Delft.

[15] U. D. Nielsen, "Transformation of a wave energy spectrum from encounter to absolute domain when observing from an advancing ship," Applied Ocean Research, vol. 69, pp. 160-172, 2017.

[16] S. Steen, Ø. Selvik, and V. Hassani, "Experience with rim-driven azimuthing thrusters on the research ship Gunnerus," in Proc. of HighPerformance Marine Vessels, Cortona, Italy, 2016.

[17] Datawell BV, "Directional Waverider," http://www.datawell.nl/, Accessed: 2017-08-23.

[18] Sintef Ocean, "ShipX," http://www.sintef.no/programvare/shipx/, Accessed: 2017-08-23

[19] J. J. Jensen, Load and Global Response of Ships, vol. 4 of Elsevier Ocean Engineering Book Series, Elsevier, 2001. 